\title{
Set Your Agricultural Publications Free in the HathiTrust Repository
}

\section{Robert B. McGeachin}

To cite this article: Robert B. McGeachin (2017) Set Your Agricultural Publications Free in the HathiTrust Repository, Journal of Agricultural \& Food Information, 18:1, 3-8, DOI: 10.1080/10496505.2016.1263201

To link to this article: https://doi.org/10.1080/10496505.2016.1263201

曲 Published online: 29 Dec 2016.

Submit your article to this journal $\pi$

Џll Article views: 208

View Crossmark data \lceil

Citing articles: 2 View citing articles 
PEER-REVIEWED ARTICLE

\title{
Set Your Agricultural Publications Free in the HathiTrust Repository
}

\author{
Robert B. McGeachin [] \\ Texas A\&M University Libraries, College Station, Texas, USA
}

\begin{abstract}
The HathiTrust repository contains agricultural Experiment Station and Extension Service publications from all 50 of the United States. But to freely display the post-1923 documents, HathiTrust requires a Permission Agreement form giving them a nonexclusive permission to distribute from the copyright holder. Agriculture librarians are encouraged to obtain signed Permission Agreement forms for the agricultural publications in HathiTrust from their state. Once Permission Agreement forms are obtained from your local copyright holding administrators, submit them to HathiTrust at (feedback@issues.hathitrust.org).
\end{abstract}

\section{ARTICLE HISTORY}

Received 29 September 2016

Accepted 17 November 2016

\section{KEYTERMS}

agricultural documents; open access; digital repositories; HathiTrust; copyright; permission agreement

\section{Introduction}

Before joining the HathiTrust Repository, the Texas A\&M University Libraries digitized retrospective publications of Texas A\&M AgriLife Research (formerly known as the Texas Agricultural Experiment Station, abbreviated TAES) and Texas A\&M AgriLife Extension (formerly known as the Texas Agricultural Extension Service, abbreviated TAEX) and made them freely available in the Texas A\&M University Libraries OAKTrust institutional repository at (http://oaktrust.tamu.edu/handle/1969.1/2827). In collaboration with the Agricultural Communications Department of Texas A\&M AgriLife Extension, since 2009, the Texas A\&M University Libraries have also been providing mirror copies of current agricultural publications in the OAKTrust repository at (http://oaktrust.tamu.edu/handle/1969.1/3684). As a collection interface, the Texas A\&M University Libraries have created Texas FARMER (Full-text Agriculture Resource Materials Repository) at (http://digital.library.tamu.edu/digitalcollections/texasfarmer/texas-farmer.html) for these and other agricultural materials in the OAKTrust digital repository. There are at least 11 titles of series that have been produced by the TAES and TAEX and are in-line for digitization.

One of the reasons for digitizing the retrospective agricultural publications was as a means of digital preservation. The earliest publications date from 1888 and the

CONTACT Robert B. McGeachin r-mcgeachin@library.tamu.edu E Texas A\&M University Libraries, Texas A\&M University, TAMU 5000, College Station, TX 77843-5000, USA.

Published with license by Taylor \& Francis. ๑ Robert B. McGeachin 
paper, through the 1950s, is discolored brown and has become brittle, with portions of pages breaking off very easily. A number of the titles were microfilmed for preservation in a nationwide project in 1980 to 1982, but the microfilm, located in only a few Land Grant University Libraries, is not widely accessible. Therefore, to both preserve and improve accessibility, the agricultural publications have been digitized to preservation standards with a TIFF image of each page scanned and a working copy of each document created as a PDF file. For each publication, these files have been loaded with corresponding descriptive bibliographic and indexing metadata into the OAKTrust digital repository. The first publication series completed, with 1,536 documents, is the Bulletin of the Texas Agricultural Experiment Station available at (http://oaktrust.tamu.edu/handle/1969.1/2829).

In addition to scholarly value for agricultural historians, these older agricultural publications are of current use for a wide variety of information seekers. They contain organic farming methods, listings of heirloom varieties of plants and breeds of livestock, the earliest scientific descriptions of insect pests and plant and animal diseases, rural sociology, cooking, food preservation, and recipes. For example, for marinade and cooking recipes for beef fajitas, see the Bulletin at (http://oaktrust.tamu.edu/handle/1969.1/147901) and, for the recipe for baking Czech kolaches, see (http://oaktrust.tamu.edu/handle/1969.1/86419). A fastgrowing group of "farmers" in many suburban and rural areas is small-scale hobby and "back to the land" families. The technological level and farming scale represented in these older publications may be more appropriate for them than more current publications aimed at the highly mechanized modern farms. With their accessibility worldwide, the older technology also may be more appropriate in lesser developed areas or, at least, serve as a resource for extension personnel to consult.

\section{HathiTrust, a shared digital repository}

The HathiTrust repository was started in 2008 by a collaboration of universities from the Committee on Institutional Cooperation and the University of California system to share digital collections (HathiTrust, 2015). "HathiTrust is a partnership of major research institutions and libraries working to ensure that the cultural record is preserved and accessible long into the future. There are more than 100 partners in HathiTrust, and membership is open to institutions worldwide" (HathiTrust, 2016, para. 1). The HathiTrust repository contains, at present, about 14.6 million volumes, with 7.3 million book titles and 402,380 serial titles. Currently, about 5.6 million of these volumes (39\% of the total) are in the public domain and freely accessible to the world.

A large percentage of the initial public domain portion of the materials in HathiTrust came from digital documents produced by the Google Book Project (GBP). The libraries that provided materials for the GBP received digital copies and were able to have them ingested into HathiTrust (Eichenlaub, 2013). A current search of the HathiTrust catalog (https://babel.hathitrust.org/cgi/ls?a=page;page= advanced) with an advanced search for "this exact phrase" = "Agricultural 


\author{
AGREEMENT BETWEEN \\ Texas A\&M AgriLife Research by and through its Director, Craig L. Nessler \\ AND The University of Michigan Library CONCERNING (Title and full citation): \\ All of Texas A\&M AgriLife Research's "Research Bulletins", Texas A\&M AgriLife Communications, 1888 et seq.
}

I, Texas Asm Agrute Reseacen by and through is Director, Craig L Nessier , hereby authorize the University of Michigan to produce digital copies of the above named publication ("the Work") for its library collection and for the HathiTrust repository. In addition, I authorize the University of Michigan to make the full text of this publication available to the public in digital form via the HathiTrust repository without restrictions.

Please select additional options if desired (initial please):

I authorize the University of Michigan to make and distribute reprints or other paper copies of the $d x$ work for noncommercial scholarly purposes.

$\mathrm{CN}$ I direct the University of Michigan and HathiTrust to apply the Creative Commons license selected below to the Work,

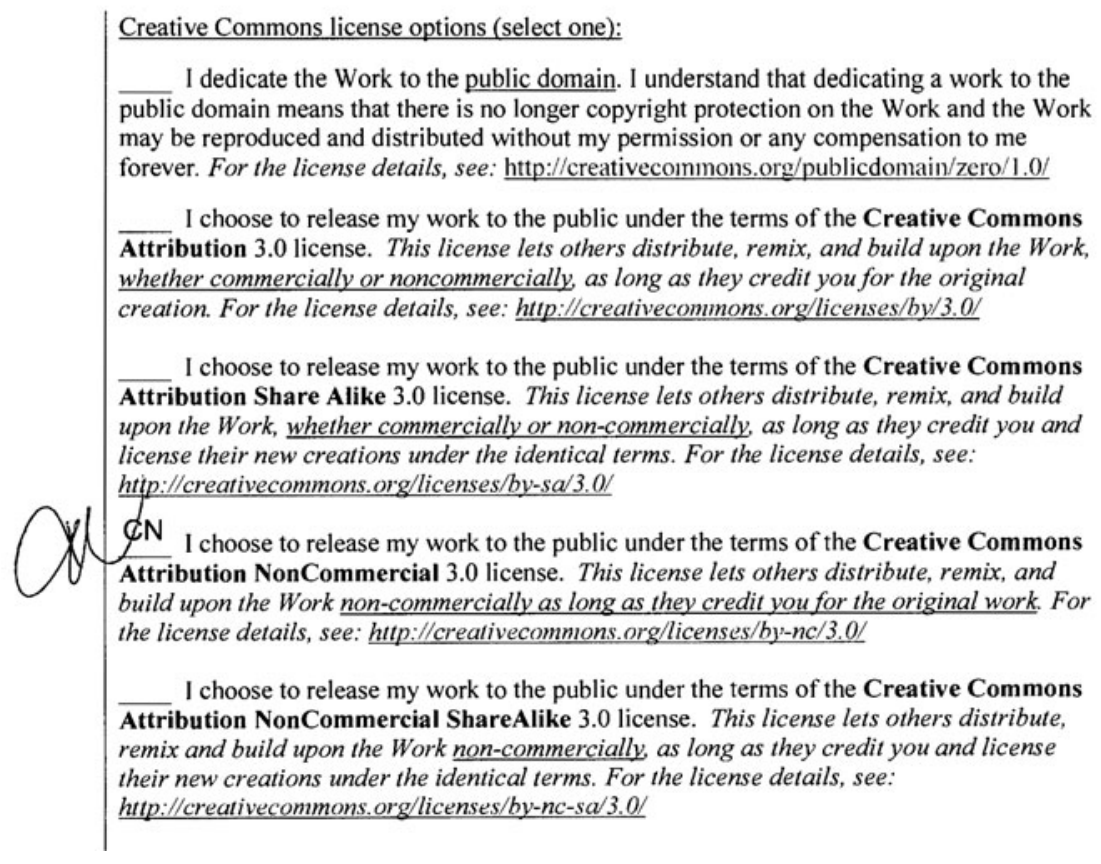

Figure 1. Example of a Permission Agreement for Bulletin of the Texas Agricultural Experiment Station submitted to HathiTrust.

Experiment Station" in "full-text and all fields" AND "all of these words" = "Bulletin" in "Title" retrieved 77,957 items. This same search modified with a "limit to" "Year of publication" "During or After 1923" yielded 48,747 items, most of which are restricted to only catalog view. So $37.5 \%$ of the Agricultural Experiment Station Bulletin items, the precopyright era, are freely available, but most of the remaining $62.5 \%$ are limited to catalog records only. The only available post-1923 items are from either Texas or Hawaii, which have submitted Permission Forms. A similar search of "Agricultural Extension Service" and "Bulletin" found a total of 13,445 


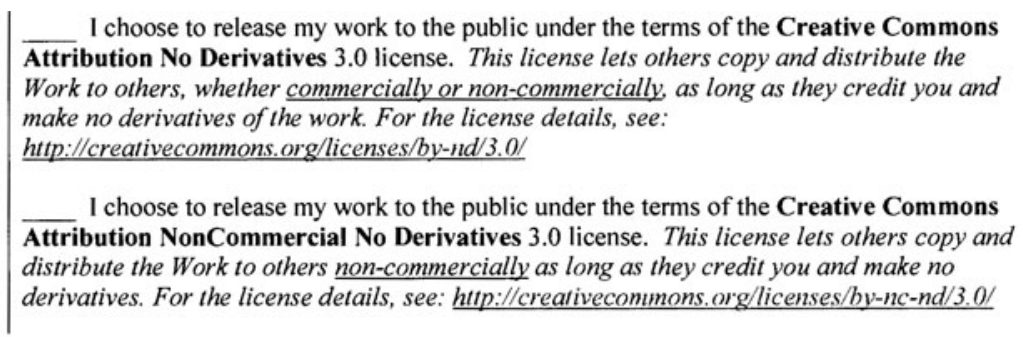

I represent and warrant to the University of Michigan that I am a copyright holder of the Work with the right to make this authorization because (please initial the appropriate reason):

cN

I still possess the original copyright that I obtained as author or publisher;

the publisher or other legal owner transferred the copyright back to me;

I obtained the copyright by transfer, gift, divorce decree, or inheritance;

other (please specify)

I also represent that the Work does not, to the best of my knowledge, infringe or violate any rights of others. I further represent and warrant that I have obtained all necessary rights to permit the University of Michigan to reproduce and distribute the Work and that any third-party owned content is clearly identified and acknowledged within the Work.

It is understood that this authorization constitutes a non-exclusive, perpetual license, and that I retain all other rights to this work to which I as copyright holder am entitled.

Name Craig L. Nessler, Director, Texas A\&M AgriLife Research

Address 2142 TAMU, College Station, TX 77843-2142

Email Address help@agrilife.org

Phone 979-845-8486

Signature

Date

$\underbrace{}_{0 / 30 / 20,3}$

Please fax, email or mail the completed form to the address below:

Library Information Technology, University Library, 818 Hatcher South, University of Michigan Ann Arbor, MI 48109-1205 | Fax: 734.763.5080| Phone: 734.764.8016 | feedback@issues.hathitrust.org

Figure 1. (continued).

items, and the "limit to during or after 1923" reduced the retrieval to 11,352 items. Since the Extension Service publications started in 1914 (as opposed to the Experiment Station publications which started in 1888), a smaller number exist in the precopyright era, so $84 \%$ are limited to catalog only and await Permission Agreements to set them free.

In 2013, the author searched and surveyed the HathiTrust collection and found a variety of Agricultural Experiment Station and Agricultural Extension Service Bulletins published by each state of the United States of America. There are also other agricultural serials such as leaflets, circulars, and technical reports from the Experiment Stations and Extension Services of many states. Although the intent of many 
states is to place these materials in the public domain for as wide a circulation as possible, HathiTrust has had to take a conservative approach to digital distribution of items in the repository and has only automatically opened items published pre-1923 to full view. For all items from 1923 and forward, they require a copyright-holdersigned Permission Agreement to open them up to full view (Levine, 2010; University of Michigan, 2016). The author, for example, has obtained a signed Permission Agreement from the Director of Texas A\&M AgriLife Research for the Bulletin of the Texas Agricultural Experiment Station which was submitted to HathiTrust, allowing HathiTrust to open full view of this title for the years 1888 through 1998, for copies submitted by both Texas A\&M University Libraries and six other academic libraries. This example Permission Agreement is shown in Figure 1.

In addition to submitting the signed Permission Agreement to (feedback@issues.hathitrust.org) for each title you want to have set to full view (https://www.hathitrust.org/permissions_agreement), it is helpful to include the volume (item identifier) or catalog record number for the serial title (A. Zaystev, personal communication, January 13, 2016). The item identifier is a unique letter and number combination assigned by the institution that submits that item to HathiTrust so the item's MARC catalog record, page image files, and page text files are all connected. The catalog record number is the record number assigned by HathiTrust for an item described by that catalog record. For example, here is an item identifier from the URL of a Texas Agricultural Experiment Station Bulletin: (https://babel.hathitrust.org/cgi/pt?id= txa.tarb002819). The identifier is txa.tarb002819; the corresponding item's catalog record is (https://catalog.hathitrust.org/Record/100007913). HathiTrust can generate reports of items held for a state upon request to aid in finding what they already have and the corresponding catalog record numbers.

\section{Conclusion}

The author, working with the Head of the Texas A\&M AgriLife Extension Agricultural Communications Department, has obtained Permission Agreements for all publication titles from the Director of Texas A\&M AgriLife Research and the Director of Texas A\&M AgriLife Extension. As a result, many of the Texas agricultural documents are now freely available worldwide in HathiTrust.

There are at least 60,000 post-1923 agricultural publications in the HathiTrust collection that are currently restricted to display of only their catalog records. Librarians should explore working with their local Agricultural Communications or Extension Publications departments to make the post-1923 agricultural content of their state's publications freely available in HathiTrust. Once agreements have been made as to which Experiment Station and Extension Service documents will be released, librarians are encouraged to obtain and submit Permission Agreement forms and lists of corresponding HathiTrust catalog record numbers to HathiTrust to make the full documents freely available. 


\section{ORCID}

Robert B. McGeachin — http://orcid.org/0000-0002-5934-8808

\section{References}

Eichenlaub, N. (2013). Checking in with Google Books, HathiTrust, and the DPLA. Computers in Libraries, 33(9), 4-9.

HathiTrust. (2015). About: Our partnership. Retrieved from https://www.hathitrust. org/partnership

HathiTrust. (2016). Welcome to the shared digital future: HathiTrust is a bold idea with big plans. Retrieved from https://www.hathitrust.org/about

Levine, M. (2010, April). Opening up content in HathiTrust: Using HathiTrust permissions agreements to make authors' work available. Retrieved from http://publications.arl.org/rli/rli269/15

University of Michigan. (2016). Permissions agreement. Retrieved from https://www.hathitrust. org/documents/permissions_agreement.pdf 